\title{
Partial discharge characteristics during electrical tree growth in LDPE
}

DOI:

10.1109/ICD.2018.8468495

\section{Document Version}

Accepted author manuscript

Link to publication record in Manchester Research Explorer

\section{Citation for published version (APA):}

Rowland, S., \& Zheng, H. (2018). Partial discharge characteristics during electrical tree growth in LDPE. In 2018 IEEE 2nd International Conference on Dielectrics, ICD 2018 (pp. 160DUMMY). [8468495] (2018 IEEE 2nd International Conference on Dielectrics, ICD 2018). IEEE. https://doi.org/10.1109/ICD.2018.8468495

\section{Published in:}

2018 IEEE 2nd International Conference on Dielectrics, ICD 2018

\section{Citing this paper}

Please note that where the full-text provided on Manchester Research Explorer is the Author Accepted Manuscript or Proof version this may differ from the final Published version. If citing, it is advised that you check and use the publisher's definitive version.

\section{General rights}

Copyright and moral rights for the publications made accessible in the Research Explorer are retained by the authors and/or other copyright owners and it is a condition of accessing publications that users recognise and abide by the legal requirements associated with these rights.

\section{Takedown policy}

If you believe that this document breaches copyright please refer to the University of Manchester's Takedown Procedures [http://man.ac.uk/04Y6Bo] or contact uml.scholarlycommunications@manchester.ac.uk providing relevant details, so we can investigate your claim.

\section{OPEN ACCESS}




\title{
Partial discharge characteristics during electrical tree growth in LDPE
}

\author{
Hualong Zheng, Simon Rowland \\ School of Electrical and Electronic Engineering \\ University of Manchester \\ Manchester, UK
}

\begin{abstract}
Partial discharge (PD) measurements were performed during an electrical treeing process in a classical needle-plane low density polyethylene sample under AC voltage. This treeing process features an evolution from the propagation of a non-conducting electrical tree to the generation of a conducting electrical tree. PD characteristics are discussed with regard to different treeing stages during the process. It is found that changes in PD characteristics occur before transitions in the visual aspect of treeing development. In particular, statistical parameters obtained from measurements reveal a polarity dependence in PD patterns in the $\mathrm{AC}$ cycle. In general, during non-conducting tree growth, positive and negative discharges are not symmetric in magnitude or phase of occurrence. Positive discharge patterns are more stable in time than negative discharge patterns. The discharge frequency and magnitude seems to have an inverse relationship for negative discharges. Negative PD patterns were found to change during periods of fast tree growth. This was not the case for positive PD patterns.
\end{abstract} effect.

Keywords—electrical tree; partial discharge; LDPE; polarity

\section{INTRODUCTION}

The polarity effect on electrical treeing degradation is generally discussed for DC stressing. Ieda [1] reported that the tree initiation voltage is higher when negative DC is applied to the needle electrode in a pin-plane sample of low density polyethylene (LDPE). The authors have previously identified that the DC voltage required for an electrical tree to grow in an epoxy resin is lower under positive polarity [2-3]. The polarity effect on tree initiation and growth under DC voltages are generally attributed to space charge distribution. Specifically, more negative charges could be injected into the dielectric from either the metallic electrode or the electrical tree tips and thus reduce the maximum electrical field at the interface between the defects and the insulation matrix. The polarity effect is rarely discussed in the context of partial discharge (PD) characteristics for electrical tree growth under AC voltages. Unbalanced discharges between positive and negative voltage half cycles were reported during the early treeing stages following tree initiation in [4]. In addition, the authors have observed an asymmetry between positive and negative discharges during the growth of a PD (non-conducting) tree in epoxy resin [5]. However, modeling of PD events associated with tree growth normally assumes symmetric parameters [6]. Nonetheless, an analysis of the asymmetric nature of PD is helpful in understanding PD behavior and providing an experimental basis for parameterizing simulation models. This work is dedicated to showing the characteristics of asymmetric partial discharges particularly with regard to different stages of electrical tree growth in a LDPE sample.

\section{EXPERIMENTAL}

The sample used for electrical treeing tests was of a needleplane geometry, fabricated by inserting a metallic needle electrode into a LDPE block at an elevated temperature of $130^{\circ} \mathrm{C}$. The LDPE block had dimensions of $30 \mathrm{~mm} \times 25 \mathrm{~mm} \times$ $3.15 \mathrm{~mm}$ and the needle (supplied by Ogura) had a tip radius of $3 \mu \mathrm{m}$ and a trunk diameter of $1 \mathrm{~mm}$. The needle tip was separated from the lower sample surface by $2.27 \mathrm{~mm}$ (i.e. the insulation thickness between electrodes). After inserting the needle electrode, the sample was maintained at high temperature $\left(130^{\circ} \mathrm{C}\right)$ for over an hour before being allowed to naturally return to room temperature at a cooling rate of less than $0.45^{\circ} \mathrm{C} / \mathrm{min}$.

A schematic of the experimental set-up is shown in Fig. 1. The sample was clamped onto a brass plate acting as a ground electrode. An HV amplifier (Trek ${ }^{\circledR}$ ) applied $50 \mathrm{~Hz} 12 \mathrm{kV}_{\mathrm{PK}}$ AC voltage to the needle electrode via a $10 \mathrm{M} \Omega$ currentlimiting resistor. A dummy sample was connected in parallel with the test sample to compose a balanced circuit for PD measurement using an Omicron MPD 600 system. The treeing test was performed at an ambient temperature of $25 \pm 2{ }^{\circ} \mathrm{C}$. The

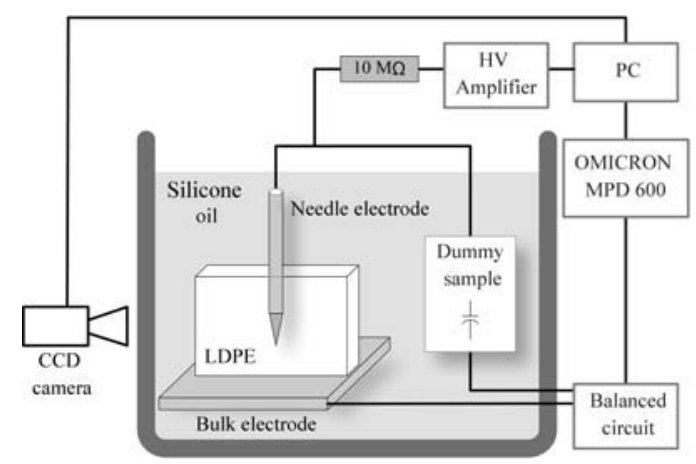

Fig. 1. Experimental set-up for real-time imaging of electrical tree growth and simultaneous partial discharge measurement. 
test cell was immersed in a silicone oil bath to eliminate corona discharges at the HV connections. The development of the electrical tree structure was recorded using a CCD camera.

\section{RESULTS}

\section{A. Electrical tree growth}

The electrical tree growth was measured by both the tree length $L$, which is the longest distance between the needle tip and tree tips in the direction of the needle axis, and the tree area $A$, which is the total number of pixels representing the tree structure in the two-dimensional images. For convenience of comparison, both $L(t)$ and $A(t)$ are normalized in Fig. 2 and are plotted together with the discharge magnitude $\mathrm{Q}_{\mathrm{IEC}}$ determined by the Omicron system. The $\mathrm{Q}_{\mathrm{IEC}}$ values were each acquired over a period of $300 \mathrm{~ms}$. A 9-second moving-average is shown in Fig. 2.

The visible aspect of the tree growth is demonstrated in Fig. 3 by only showing the newly developed parts of the tree structures in five consecutive time periods. During the first $3000 \mathrm{~s}$ of voltage application, a typical branch-type electrical tree was initiated from the needle tip and grew towards the plane electrode. However, during $3000 \mathrm{~s}-5000 \mathrm{~s}$ (Fig. 3c), although there was apparent extension in tree length, the major increase in tree structure can be attributed to short branches growing out of the existing long tree channels. Afterwards, those new branches kept developing during the next period of $5000 \mathrm{~s}-12000 \mathrm{~s}$, while the overall tree length barely increased. Comparing Figs. $3 \mathrm{~b}$ and $3 \mathrm{e}$, it is clear that tree growth after $12000 \mathrm{~s}$ was different in morphology. The tree is composed of short and dense pine-tree branches growing out of a few thick main tree channels. Unlike the branch trees, tree growth after $12000 \mathrm{~s}$ was not necessarily following the expected maximum electrical potential gradient, as indicated by the tree branches which have propagated sideways in Fig. 3e.

\section{B. PD characteristics}

The Omicron PD measurement device records the time, the discharge magnitude (in Coulombs) and the phase of voltage of each PD occurrence. Based on this raw data, several statistical parameters were calculated for every voltage cycle for positive and negative discharges separately. The time variations of these statistical parameters illustrated in Fig. $4 \mathrm{a}-4 \mathrm{c}$ are the numbers of discharges (per cycle) $N_{p d}$, the mean discharge magnitudes $Q_{m}$, and peak discharge magnitudes $Q_{p k}$ (namely the maximum positive and minimum negative discharges). For clarity of display, a moving average over $1 \mathrm{~s}$ was applied to $N_{p d}$ and $Q_{m}$, while the $Q_{M}$ displayed was averaged over 9 s. Fig. $4 d$ plots the density distribution of the phase of PD occurrences over every $10 \mathrm{~s}$. Typical phase-resolved PD (PRPD) patterns are given in Fig. 5 at four periods of $20 \mathrm{~s}$ measured at different times.

Fig. 4 shows that the statistical values are not balanced between positive and negative discharges at a given time. Most of the time, positive discharges are fewer in $N_{p d}$ but higher in $Q_{m}$ and $Q_{p k} . N_{p d}$ maintained a stable level between $\sim 200 \mathrm{~s}$ and $\sim 8000 \mathrm{~s}$, while spikes in $N_{p d}$ were observed for negative discharges. Fig. 4d shows that following tree initiation the phase of positive discharges soon became regular. This

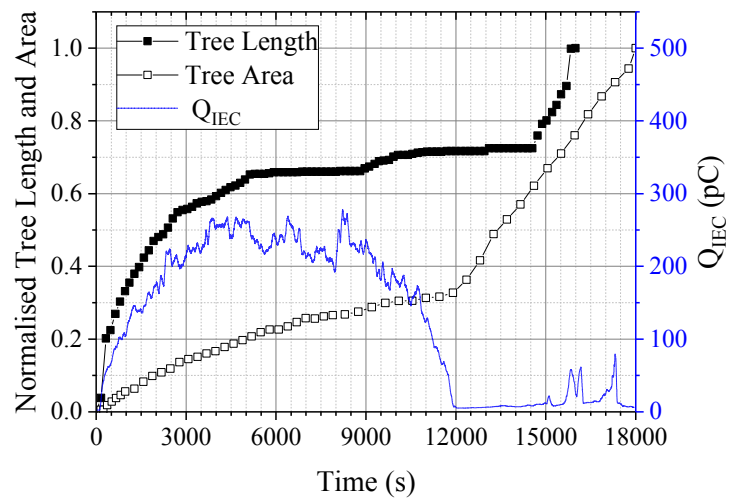

Fig. 2. Developments of the length and area of the electrical tree structure during 5 hours of voltage application. Also shown are the apparent discharge magnitudes $\mathrm{Q}_{\mathrm{IEC}}$. The tree length and area are normalized to their ultimate values for the convenience of comparison.

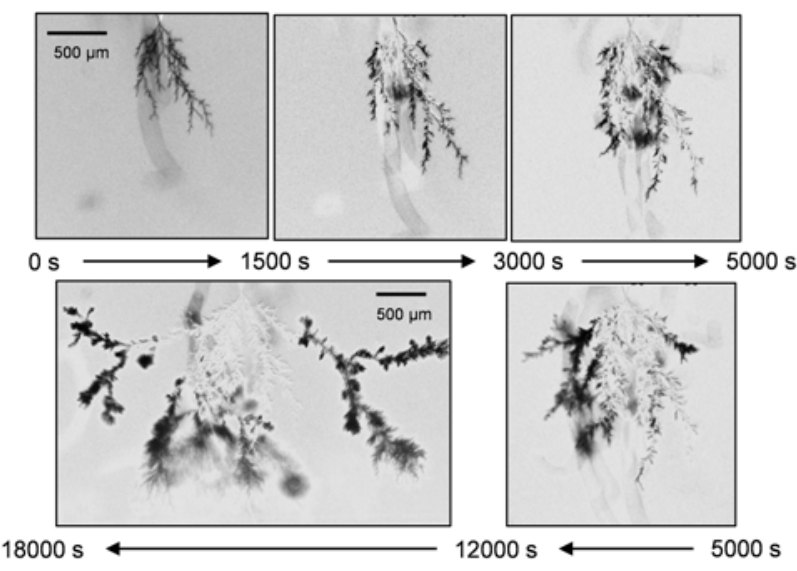

Fig. 3. The electrical tree shown after five periods. The newly developed parts of the tree structures are displayed in black. These images were obtained by subtracting the previous tree images from the current image. Times are listed below the tree images. The scaler bar in (a) also applies to all images (b) - (d).

appeared as PD clusters in PRPD patterns as shown in Fig. 5a$5 \mathrm{c}$. The formation of PD clusters in the negative voltage phase lags that in the positive voltage phase. However, PD clusters vanished in both positive and negative discharges after $8000 \mathrm{~s}$ as can be witnessed by the PRPD pattern in Fig. $5 \mathrm{~d}$.

\section{DISCUSSION}

The visual aspect of the electrical trees shown in Fig. 3, and the corresponding PD measurements in Fig. 2, suggest that there were two types of electrical tree growth during the 5 hours of voltage application. This resulted in conducting and non-conducting tree growth as defined in [7]. During the first period of about $4000 \mathrm{~s}$, a nearly linear relationship between tree length and discharge magnitudes ( $\left.\mathrm{Q}_{\mathrm{IEC}}\right)$ can be found in Fig. 2, indicating that the tree belongs to the non-conducting tree category. After $12000 \mathrm{~s}$, the PD Q $\mathrm{IEC}$ magnitudes were about two orders of magnitude smaller. Together with the branchpine tree shape, as reported in [8], it can be concluded that the 


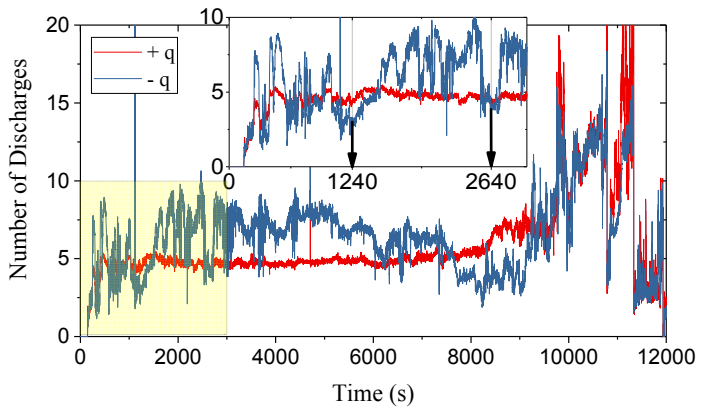

(a)

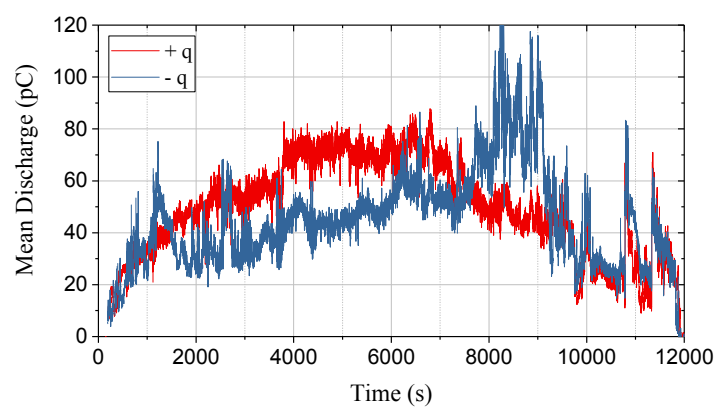

(b)

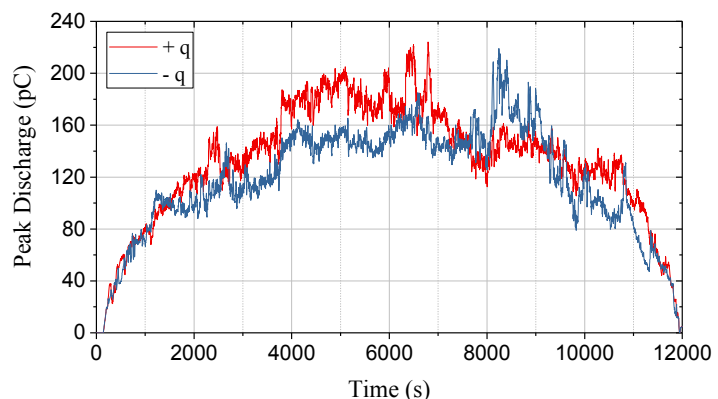

(c)

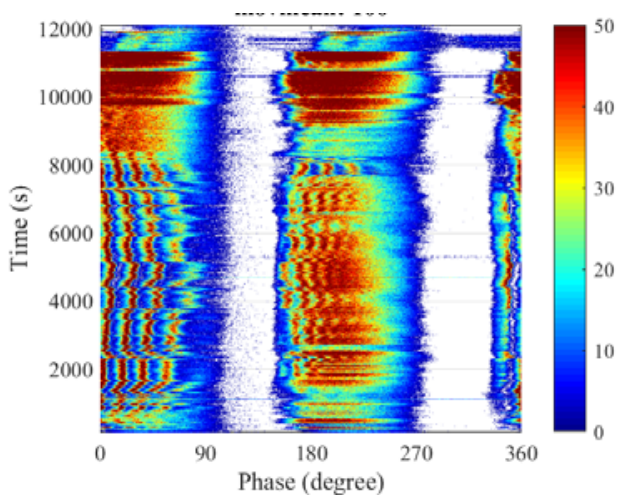

(d)

Fig. 4. Time variation of statistical parameters obtained from PD measurements. (a) is the number of discharges per voltage cycle $\mathrm{N}_{\mathrm{pd}}$. (b) is the mean discharge magnitude $\mathrm{Q}_{\mathrm{m}}$. (c) is the peak discharge magnitude $\mathrm{Q}_{\mathrm{pk}}$. A moving average over $1 \mathrm{~s}$ was applied to (a) and (b). (c) is a moving average over $9 \mathrm{~s}$. (d) is the density distribution of the phase of PD occurrences over every $10 \mathrm{~s}$ period. The color bar shows the number of PDs in each period.

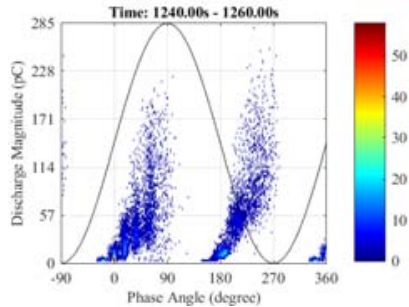

(a)

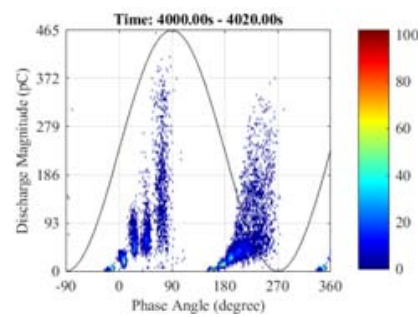

(c)

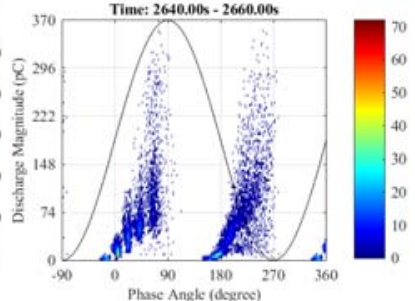

(b)
Fig. 5. Phase-resolved PD patterns at 4 distinct times over $20 \mathrm{~s}$. Color bars show the number of discharges over $20 \mathrm{~s}$.

tree growth at $12000 \mathrm{~s}$ was of a conducting tree in which PDs were suppressed within the main tree channels but were concentrated at tree tips. During the period $5000 \mathrm{~s}-12000 \mathrm{~s}$, the gradual reduction of $\mathrm{Q}_{\mathrm{IEC}}$ values indicates a transition period between these two tree types. Consequently, based on the visual aspect of tree growth (i.e. $L$ and $A$ ), the treeing process can be described in 3 stages:

- Treeing Stage 1: non-conducting tree developing in length before $4000 \mathrm{~s}$.

- Treeing Stage 2: tree growing sideways between $4000 \mathrm{~s}$ and $12000 \mathrm{~s}$, and evolving into a conductive structure

- Treeing Stage 3: conducting tree growth after $12000 \mathrm{~s}$.

Nevertheless, the complex PD dynamics illustrated in Fig. 4 suggest that the transitions between the above three treeing stages are not abrupt. For example, PD events can be seen to form consistent features in Fig. 4 between about $1500 \mathrm{~s}$ and $7500 \mathrm{~s}$. This period, however, started before the middle of Treeing Stage 1 and ended just past the middle of Treeing Stage 2. Moreover, in Treeing Stage 2 (4000 s - $12000 \mathrm{~s})$, the PD statistics became clearly different after about 8000 s. If only judging from the $\mathrm{PC}$ characteristics, three stages can be distinguished before the PDs reduced in magnitude after $12000 \mathrm{~s}$ as following:

- PD Stage 1: unstable negative discharges until $1500 \mathrm{~s}$

- PD Stage 2: asymmetric discharges between 1500 and $7750 \mathrm{~s}$.

- PD Stage 3: diminishing PDs after $8000 \mathrm{~s}$.

In general, the shifts between PD stages occur before the transitions in visible treeing stages. Therefore, an analysis of PD characteristics can be used for the prediction of electrical tree growth. For example, asymmetric discharges such as those in PD Stage 2 may be an indicator of the formation of a stable tree structure (i.e. Treeing Stage 2). The decrease in measured $\mathrm{Q}_{\text {IEC }}$ values together with a surge of small discharges may predict the generation of conducting trees. 
The polarity effect on PD events during the typical nonconducting tree growth phase appears in two aspects. Firstly, discharges are not symmetric between positive and negative discharges. Secondly, the abrupt changes in discharge statistics only occurred for negative discharges.

A typical PD pattern of asymmetric discharges is shown in Fig. 5c. Both positive and negative discharges increase with rising point-on-wave voltage amplitude. The shape of the PD pattern indicates that the tree length was not limiting the PD propagation, otherwise the PD pattern would be turtle-like, as shown in [9]. Assuming discharge magnitudes are in proportion to the length of the PD path, the asymmetric discharges suggest that the positive discharges propagate a longer distance within tree channels than negative discharges. This is consistent with the observation on the propagation of discharge streamers in oil insulation [10].

During typical non-conducting tree growth (Treeing Stage 1) negative discharges could occasionally be higher than or equal to positive discharges in magnitude. Typical PD patterns for these two scenarios are given in Fig. $5 \mathrm{a}$ and $5 \mathrm{~b}$. However, there is no fundamental difference between the shape of PD patterns in Fig. 5a, 5b and 5c. There are two differences between discharge patterns associated with positive and negative polarities. Firstly, in the positive cycle discharges tend to occur in small clusters at particular phases, a feature only seen later in the negative half cycle (Figure 4(d)). Secondly, the negative discharge pattern consists of a combination of many smaller magnitude discharge events and a smaller number of larger discharge events. Therefore, any period of balance in the discharges across the polarities can be regarded as a transient condition during the dynamics of negative discharges. It has been suggested that only the discharges that propagate to tree tips lead to growth in tree length [11]. Since, in some periods, negative discharges can be larger than positive, in these times it may be that negative discharges are key to tree growth. This agrees with the experimental results in that more negative discharge dynamics (for instance the sags in $N_{p d}$ in Fig. 4a) were observed during the fast tree growth in Treeing Stage 1.

\section{CONCLUSION}

This work reports the PD characteristics of an electrical treeing process in a LDPE sample of needle-plane geometry. This treeing process features a clear transition from the growth of a non-conducting (PD) electrical tree initiated at the needle electrode to the growth of a conducting electrical tree structure. Treeing and PD features have been described in three distinct stages. The fact that PD patterns evolved in advance of changes in physical treeing growth stages may imply that PD measurements of this sort can be used for assessing the nature of treeing degradation.

PD measurements also revealed polarity-dependent PD characteristics for non-conducting tree growth. In most cases, discharges are asymmetric between positive and negative voltage half-cycles. The asymmetric PDs were characterized by a few statistical parameters, including the discharge frequencies, phase of discharges, mean and peak discharge magnitudes. All these time-dependent parameters suggest that during non-conducting tree growth, positive discharges are more stable than negative discharges, while spikes in values of negative discharges were observed in time. When negative discharges are more frequent than positive discharges, they are smaller in magnitude, and vice versa. Symmetric discharges occasionally occur as a consequence of the transition between states of negative discharges. In addition, the dynamics of negative discharges change more frequently during fast tree growth, while their patterns are more stable in a relatively stable tree structure. The PD characteristics reported in this work provide a basis for further modeling activity to incorporate the asymmetric nature of discharges under $\mathrm{AC}$ voltages.

\section{ACKNOWLEDGMENT}

The authors are grateful to the EPSRC for support of this work through the project 'Towards Enhanced HVDC Cable Systems', EP/L021560/1.

\section{REFERENCES}

[1] Ieda and Nawata, "DC Treeing Breakdown Associated with Space Charge Formation in Polyethylene," IEEE Trans. Electr. Insul., vol. EI12, pp. 19-25, 1977.

[2] I. Iddrissu, H. Zheng, and S. M. Rowland, "DC electrical tree growth in epoxy resin and the influence of the size of inceptive AC trees," IEEE Trans. Diel. Electr. Insul., vol. 24, pp. 1965-1972, 2017.

[3] I. Iddrissu, Z. Hualong, and S. M. Rowland, "Electrical tree growth in epoxy resin under DC voltages," IEEE Conf. Solid Dielectr. (ICD), vol. 2, pp. 820-823, 2016

[4] H. Naohiro, O. Tatsuki, and F. Hiromasa, "Simultaneous Measurement of Microscopic Image and Discharge Pulses at the Moment of Electrical Tree Initiation," Jpn. J. Appl. Phys., vol. 27, pp. 572-576, 1988.

[5] H. Zheng and S. M. Rowland, "Electrical treeing in a glassy epoxy resin - the filamentary tree and the PD tree," IEEE Conf. Electr. Insul. Dielectr. Phenomena (CEIDP), pp. 765-768, 2017.

[6] S. J. Dodd, N. M. Chalashkanov, and J. C. Fothergill, "Partial discharge patterns in conducting and non-conducting electrical trees," IEEE Conf. Solid Dielectr. (ICD), pp. 1-4, 2010.

[7] J. V. Champion and S. J. Dodd, "Simulation of partial discharges in conducting and non-conducting electrical tree structures," J. Phys. D Appl. Phys., vol. 34, p. 1235, 2001.

[8] X. Chen, Y. Xu, X. Cao, and S. M. Gubanski, "On the conducting and non-conducting electrical trees in XLPE cable insulation specimens," IEEE Trans. Diel. Electr. Insul., vol. 23, pp. 95-103, 2016.

[9] W. Kai, Y. Suzuoki, T. Mizutani, and X. Hengkun, "A novel physical model for partial discharge in narrow channels," IEEE Trans. Diel. Electr. Insul., vol. 6, pp. 181-190, 1999.

[10] Y. Li, J. Y. Wen, Y. Liang, J. Wu, S. Qin, and G. J. Zhang, "Streamer discharge propagation and branching characteristics in transformer oil under AC voltage: Partial discharge and light emission," Int'l. Conf. Dielectric Liquids (ICDL), pp. 1-4, 2017.

[11] Z. Lv, S. M. Rowland, S. Chen, H. Zheng, and I. Iddrissu, "Evolution of partial discharges during early tree propagation in epoxy resin," IEEE Trans. Diel. Electr. Insul., vol. 24, pp. 2995-3003, 2017. 